\title{
Management of employee workplace learning: a means of sustainable development in small manufacturing enterprises in Nigeria
}

\author{
J. I. Ogolo \\ Department of Business Administration, \\ Niger Delta University, Wilberforce Island, Bayelsa, Nigeria
}

\begin{abstract}
The paper has as its main objective to contribute to an understanding of effects of management in employee workplace learning for sustainable development in small manufacturing enterprises in South East Nigeria. The research design was a survey method while the sampling procedure used for the study was a combination of systematic and judgmental sampling. Using the Taro Yameni formula the sample of 375 was obtained from a population of 6,000 small manufacturing enterprises, in five states in South East Nigeria. The data used for the study were gathered from both primary and secondary sources. A questionnaire was developed to capture the employees' perception of human resources management practice policies with regard to the suitability of their development. The questionnaire comprised of questions in line with the objectives. Some managers were also interviewed to corroborate and strengthen results obtained from the questionnaire. Using the statistical package for social sciences (SPSS), a range of statistical methods was employed to analyze the survey data. Correlation analysis was used to analyze associative relationship between the measures of work environment characteristics, as provided by the human resource department and source of learning on the one hand, and the measure of satisfaction with reference to outcome of workplace learning experiences on the other. The results relating to sources of learning suggested that managers were an important part of the employees' learning network and did make useful contributions through developmental interventions such as delegation and coaching. However, workmates were perceived by employees to be more useful sources of work related learning than the managers. Finally, specific managerial actions and behaviors that had the potential to increase
\end{abstract}


employee sustainable development with workplace learning were recommended, including the use of the researcher's cybernetic sustainable model.

Keywords: employee workplace learning, human resource management, small manufacturing enterprises, sustainable development, effect of management, economic growth, coaching, mentoring, human resource development, environmental condition of workplace learning.

\section{Introduction}

Management of small manufacturing enterprises in Nigeria dates back to precolonial times. The country was then known for the manufacturing of hides and skin, calabash, foot wear, traditional wear and so on. These industries generated much of the internal and foreign exchange that sustained the economy. However, since independence and particularly the Nigeria civil war, things have changed. It has been said that micro/cottage, small and medium scale enterprises serve as the engine of economic development of any developing nation and that statistics show about 3 out of 4 of these industries die every year in Nigeria. Little wonder, 9 out of 10 persons, who wish to go into business in Nigeria, do not eventually get to start. Thus, on a daily basis, more enterprises die off than those that spring up. Most surviving enterprises hardly outlive their founders. Very few statutory corporations and state-owned companies and parastatals as well as privately owned small manufacturing enterprises (SMEs) were sustained in South-East Nigeria, described as "Nigeria's home of business minds". Yet, the zone formed most part of the former Eastern Region whose economy was once adjudged the fastest growing and industrializing economy in the world in the early 1960s. SMEs in Nigeria had a myriad of problems militating against their establishment, survival and growth (Eneh [1]).

To remain sustainable, organizations must monitor their external environments, anticipate, and adapt to continual change (Marquardt [2]). Implementation of change initiatives in organizations, such as the introduction of new technology, products or processes, usually require the acquisition of new knowledge and skills. Some commentators believe that organizations that learnt faster are able to adopt quicker and thus avoid the economic evolutionary 'weeding out' process (Schien [3]). Learning is important, not only for organizational survival, but also because the ability to learn faster than competitors might be the only sustainable competitive advantage (De Geus [4]).

Competition among companies for the best talent is fierce. Talented people choose from potential employers, not just on pay and prospects offered, but also on whether the organization has a learning culture in its core values. Security of employment can be said to be giving way to security of employability. That is, an organization should have a culture of learning (Grayson and Hodges [5]). The inability of the management of small manufacturing enterprises to put in place effective learning structure at workplace in developing human capital makes it impossible for employees to be flexible, adaptable and constantly learning to perform new and changing tasks. Although organization can no longer provide employment security, the employee's ability and willingness to learn and adapt 
are the key determinants of their employability elsewhere. As part of the new deal in employment, good employers will ensure that the employees remain employable by keeping them up to date through learning and development at workplace (Coetzer [6]).

Management in most small manufacturing enterprises has not impacted very well on the employee workplace learning for sustainable development. The conducive environment necessary for workplace learning has not been fully provided and given the right attention. The attendant effect is that it becomes very difficult for these small manufacturing enterprises to become knowledge intensive organizations. So they find it difficult to acquire the knowledge and skills needed for themselves. Moreover, they become unable to develop the human capital that is necessary for organizational growth and development. With low growth rate and low market share, some of the small manufacturing enterprises, run the risk of not achieving their organizational goals (Ile [7]).

\subsection{Objective of the study}

1. To determine the effects of human resource management practices in fostering employee work place learning for sustainable development in small manufacturing enterprises in Nigeria.

2. To determine the sources of learning the employees attribute their work related leaning for the sustainability of their development in small manufacturing enterprises in Nigeria.

3. To determine the outcome of employee learning experience in the sustainability of the development of small manufacturing enterprises in Nigeria.

\subsection{Hypotheses}

Three hypotheses were formulated and stated in null forms thus

1. There is no significant relationship between the effects of human resource management practice and fostering of employee workplace learning for sustainable development in small manufacturing enterprises in Nigeria.

2. There is no significant relationship between sources of learning in the workplace and employee work related learning for the sustainability of their development in small manufacturing enterprises in Nigeria.

3. There is no significant relationship between the outcome of employee workplace learning experience and the sustainable development of small manufacturing enterprises in Nigeria.

\section{Review of related literature}

The management process is a sequence of activities, steps or behaviours. A function of management is a work activity performed by a manager engaged in managing. Christopher Galvin being a manager, first created a clear set of goals and plans that articulated what he wanted the company to become. He also created a more effective organization to help make those goals and plans a 
reality. Galvin also pays close attention to the people who work for Motorola, and he keeps a close eye on company is performing. Each of these activities represents one of the five basic managerial functions. Setting goals is part of planning, setting up the organization is part of organizing, selecting and recruiting people is part of staffing, managing people is part of leading, and monitoring performance is part of control (Griffin [8]). It is important to note, however, that the functions of management do not usually occur in a tidy, stepby-step fashion. Managers do not plan on Monday, make decisions on Tuesday, organize on Wednesday, lead on Thursday, and control on Friday. At any given time, for example, a manager is likely to be engaged in several different activities simultaneously. Indeed, from one setting to another, managerial work is as different as it is similar. The similarities that pervade most settings are the phases in the management process. Important differences include the emphasis, sequencing, and implications of each phase (Ghoshal and Bartlett [9]).

\subsection{Concept of micro, small, medium and large business formation in Nigeria}

The national policy on MSMEs classified micro enterprises to be less than 10 employees and assets to be less than five million naira. Small enterprises to be 10-49 employees and assets between five and fifty million naira, Medium enterprises to be 50-199 employees and assets between fifty and five hundred million naira Where there exists a conflict in classification between employment and assets criteria (for example, if an enterprise has assets worth seven million naira (N7m) but employs 7 persons), the employment-based classification tends to be relatively more stable definition, given that inflationary pressures may compromise the asset-based definition. In choosing these definitions, cognizance is taken of all possible factors, including international comparisons and peculiarities of the various sub-sector/enterprises (IIe [7]).

\subsection{The meaning and nature of learning}

Learning has been defined by Kim as the process of increasing one's capacity to take action' (Kim [10]). It should be distinguished from training: 'learning is the process by which a person acquires new knowledge, skills and capabilities, whereas training is one of several responses an organization can take to promote learning (Reynold et al. [11]). A distinction between learning and development, say that learning is seen as being concerned with an increase in knowledge or a higher degree of an existing skill, whereas development is more towards different state of being or functioning (Pedler et al. [12]). Learning is not simply having a new insight or a new idea, it occurs when we take effective action and when we detect and correct error. How do you know when you know something? It is when you can produce what it is you claim to know' (Argyris [13]). Hicks [14] explains that learning means change, but change of a relatively permanent kind. Individuals may behave differently because of short-term factors such as tiredness or alcohol; these temporary changes are of a different nature to those associated with the process of learning. 


\subsection{The learning process}

Honey [15], with a number of leading authorities on learning in organizations, has declared that 'learning is complex and various, covering all sorts of things such as knowledge, skills, insights, beliefs, values, attitudes and habits'. Individuals learn for themselves and learn from other people. They learn as members of teams and by interaction with their managers, co-workers and people outside the organization. People learn by doing and by instruction. The ways in which individuals learn differ and the 'extent to which they learn depends largely on how well they are externally motivated or self-motivated. Birchall and Lyons [16] emphasize that the effectiveness of learning will be strongly influenced by the context in which it takes place. This includes the values of the organization. Is it truly believed that learning is important as a means of developing a high performance culture and achieving competitive advantage? Is this belief confirmed by actions that encourage and support learning? Is the approach to learning delivery in line with the belief that 'For effective learning to take place at the individual level it is essential to foster an environment where individuals are encouraged to take risks and experiment, where mistakes are tolerated, but where means exist for those involved to learn from their experiences? (Watkins and Marsick [17]).

\subsection{Informal learning}

Informal learning is experience learning. Most learning does not take place in formal training programmes. This is the conclusion of a US Bureau of Labour report in 1996, which indicates that people learn 70 per cent of what they know about their job informally, through processes not structured or sponsored by the organization. A study by Eraut et al. [18] establishes that in organizations adopting a learner-centred perspective, formal education and training provided only a small part of what was learnt at work. Most of the learning described to the researchers was non-formal, neither clearly specified nor planned. It arose naturally from the challenges of work. Effective learning is, however, dependent on the employees' confidence, motivation and capability. Some formal training to develop skills (especially induction training) is usually provided, but learning from experience and other people at work predominates (Armstrong [19]).

\subsection{The meaning and nature of workplace learning}

There are many definitions of workplace learning. Most of the definition involves the processes and outcomes of learning that individual employees and groups of employees take under the auspices of a particular workplace. Both the processes and outcome of learning involve changes in the meanings that individuals and all employees apply to their workplace. Learning in the workplace involves change in feelings, value, knowledge, understanding, and skills that have relevance, for particular workplace. Workplace learning comes about as a result of individual and groups of employees being both willing and able to satisfy individual, group and whole workplace needs through autonomous self-direction, supported and 
tempered by workplace-cooperation (Holiday [20]) Workplace learning encompasses several other terms including training and human resource development. Initially, training was the prevalent term, and it was appropriately refereed to as job-related instruction. Later, human resource development was coined to mean all those activities that develop people as resources for organizations (Nadlers [21]). Workplace learning encompasses what learners do rather than focusing solely on what trainers or developers do in organizations (Watkins and Marsick [22]). Workplace learning is: the way in which individuals or group acquire, interpret, reorganize, change or assimilate a related cluster of information, skills and feelings. It is also primary to the way in which people construct meaning in their personal and shared organizational lives (Marsick [23]).Workplace learning can take place in three forms, namely, the workplace as a site for learning, the workplace as a learning environment, and where learning and working are inextricably mixed (Stern and Summerland [24]).

\subsection{Human resources management practices}

Human Resource Management Practice (HRMP) policies are closely associated with that aspect of Human Resource Development (HRD), which is concerned with investing in people and developing the organization's human capital. One of the primary objectives of HRM is the creation of conditions whereby the latent potential of employees will be realized and their commitment to the causes of the organization secured. This latent potential is taken to include, not merely the capital to acquire and utilize new skills and knowledge, but also to hitherto untapped wealth of ideas about how the organization's operations might be better ordered (Keep [25]). The key elements of human resource development is: learning, education, development, and training (Buss and Vaughan [26]).

\section{Methodology}

The study is a field survey utilizing data obtained from small manufacturing enterprises in five cities of the five states of South East Nigeria. 375 copies of the questionnaire were distributed at Onitsha, Enugu, Abakiliki, Owerri and Aba. Imaga [27] opines that the survey method is "a strategy in which a representative sample of a population is studied and results generalized". It studied large and small populations by selecting and studying samples drawn from population. The primary data are gotten by interviewing the managers and the employees in the sampled small manufacturing enterprises in southeast states of Nigeria. The secondary data are collected from materials relevant to the research. These are textbooks journals, official government gazettes; Chamber of Commerce and Industries, and database offices of the National Association of Small Scale Industries in the states under review. The population of the study is drawn from the small manufacturing enterprises in the South East States of Nigeria especially from the capital or commercial cities of the States, namely Onitsha Enugu, Abakaliki, Owerri and Aba. The lists of the enterprise are collected from the National Association of Small Scale Industries (NASSI), Manufacturer Association of Nigeria (MAN), Small and Medium Enterprises Development of 
Nigeria (SMEDAN), and Chambers of Commerce and Industry in the states under study. From the secondary data, targeted population of small manufacturing enterprises in South-East Nigeria are one thousand $(1,000)$ with a total staff strength of one hundred and fifty thousand $(150,000)$ employees on full time and employment were recorded.

\subsection{Sampling procedure and sample size determination}

The sampling techniques used consisted of a combination of judgmental, convenience, quota and clustered sampling (Baridam [28]). The sample size is determined by the creation of a list containing about 90,000 employees, carefully examined to identify and remove elements that clearly did not belong to the target population (10-49 employees in each enterprise and investment valued between $\$ 5 \mathrm{~m}$ to $N 50 \mathrm{~m}$ ). Using these clean lists as the sampling frame, a systematic sampling procedure which involves selecting every third firm on the lists is employed to randomly select firms that would be invited to participate in the study. At the end of the exercise, 6,000 employees (accessible population) from 20 enterprises were selected using a judgmental method (Zikmund [29]). The Taro Yamen's formula is used to determine the sample size when the targeted population is known. According to Baridam [28] the formula is as follows:

where $\mathrm{n}=$ sample size

$$
\frac{\mathrm{n}=N}{1+N(e)^{2}}
$$

$\mathrm{N}=$ the population size

$\mathrm{e}=$ proportion of the sampling error.

For an effective representation of the various strata considerations, the percentage of the sample size (n) to the population (N) was calculated. From the accessible population of small manufacturing enterprises in South East, we have the total number of employees of 6,000 .

The percentage ratio of 30:25:20:15:10 is derived from the population size of the enterprises in the states under review.

Setting the confidence level at $95 \%$ (i.e. 0.05 level of significance), meaning that there is a 95 percent chance that the sample is distributed the same way as the population, then

$$
\mathrm{N}=6,000 \quad \mathrm{e}=0.05
$$

Substituting in Taro Yameni's formula we have,

$$
\begin{aligned}
\mathrm{N} & =\frac{6,000}{1+6,000(0.05)^{2}} \\
& =\frac{6,000}{1+(6,000 \times 0.0025)} \\
& = \\
& 375
\end{aligned}
$$

Hence, a total sample size of 375 was drawn from the accessible population. This number, 375 , is distributed judgmentally among the enterprise in the 
accessible population by using the ratios of their relative employee sizes. The ratio is about 30:25:20:15:10 for Anambra: Abia: Enugu: Imo: Ebonyi. The description and development of research instrument used for this study comprised of mail questionnaire and personal interviews using structured items (statements) that were related to effects of management of employee work place learning for sustainable development in line with the objectives. The copies of questionnaires were distributed to 375 respondents comprising owner managers, managers, supervisors and employees selected from 20 enterprises of small manufacturing enterprises in Onitsha, Enugu, Aba, Owerri and Abakiliki all in South East states.

\section{Results}

\subsection{Objective and hypothesis one}

Analysis of the interview data gathered during the qualitative part of the study suggested that the informal employee recruitment and selection practices used by managers in human resource management department, in some of the enterprises studied seemed to have unintended positive 'side' effects on employees' informal workplace learning. Specifically, those managers encouraged their existing staff to recruit new employees from their familiar and social setting, and used employee selection methods that required job candidates to demonstrate their skills on the job. The findings also suggested that when existing staff were involved in recruiting newcomers through social networks, they were likely to take the initiative in supporting those newcomers on their pathways of work related learning. Furthermore, employee selection methods that required candidates to demonstrate their skills on the job were likely to yield, as a by product, information about their learning needs. Such information assisted those who guided their learning to select tasks appropriate to the learners' level of development. In analyzing the relationship between effects of human resource management practice and fostering of employee workplace learning for sustainable development in small manufacturing enterprises, the Pearson product moment correlation coefficient was used to determine the level of relationship existing between the dependent and independent variables under study. The result of the correlation coefficient of the set of variable $\mathrm{x}$ and $\mathrm{y}$ was 0.84 . This value 0.84 suggested that the degree of correlation between the dependent variable fostering of employee workplace learning for sustainable development in small manufacturing enterprises in Nigeria and the independent variable effects of human resources management practices showed high correlation. The result suggested that the degree of relationship between the dependent variable and the explanatory variable was very strong.

\subsection{Objective and hypothesis two}

With regard to sources of learning, the findings suggested that managers in the small enterprises studied did make useful contributions to their employees' work 
related learning, through developmental interventions such as delegation and coaching. From the perspective of the employees, workplace supervisors were useful sources of learning. However, workmates were perceived by employees to be more useful sources of work related learning than were the managers. In other words, employees attributed more of their learning to their workmates, than to their current workplace supervisor or to other managers in the enterprises. In analyzing relationship between the sources of learning initiated by management in workplace and employee work related learning for the sustainability of their development in small manufacturing enterprises in Nigeria. The Pearson product moment correlation coefficient was used to determine the level of relationship existing between the dependent and independent variables under study. The result of the correlation coefficient of the set of variables $\mathrm{x}$ and $\mathrm{y}$ was 0.68 . The value 0.68 suggested that the degree of correlation between the dependent variable (sources of employee work related learning for the sustainability of their learning) and the independent variable (sources of learning initiated by management in workplace). The result suggested that the degree of relationship between the dependent variable and explanatory variables was strong. The result suggested that there is a strong positive linear relationship between the variables.

\subsection{Objective and hypothesis three}

In this study, outcomes of employee workplace learning experiences at the organizational level for the sustainable development of the SME level were gauged in terms of typical 'results' measures of work group performance: quality, complaints from internal or external customers, quantity, and costs. Results of the employee survey relating to work group performance suggested that managers in the sample enterprises were not providing sufficient staff access to information related to work group 'results' measures (Large numbers of respondents selected the undecided response option). Access to such information helped work groups to monitor their performance and progress, and that fostered learning at the individual and team levels. The apparent lack of staff access to information, relating to 'results' measures, was also suggestive that employees in those enterprises were not empowered. In analyzing the relationship between the outcomes of employee workplace learning experiences and sustainable development of small manufacturing enterprises in Nigeria. The Pearson product moment correlation coefficient was used to determine if relationship exist between the dependent and independent variables under study. The correlation coefficient result of the set of variable $\mathrm{x}$ and $\mathrm{y}$ was 0.64 . The value of 0.64 suggested that the degree of correlation between enterprises sustainable development in small manufacturing enterprises and outcomes of employee workplace learning experiences was 64 percent. The result suggested that the degree of relationship between the dependent variable and explanatory variables was strong. The result suggested that there was a strong positive linear between the independent variables and the dependent variable. 


\section{Conclusions}

Clearly, the empirical studies carried out enhanced the understanding of the effects of management on employee's learning. Although the discourses of workplace learning, organizational learning and learning organization suggested that learning should be a central concern in the workplace, evidence from this study seemed to indicate that the potential of small business organizations as sites for learning was not being fully realized. The Small Manufacturing Development Agency regarded small manufacturing enterprises (SMEs) as the vehicle that created most of the employment in the South East Nigeria, and the backbone for South-East zonal economic growth. Accordingly, development of SMEs in the South East of Nigeria had a crucial role in both new employment creation and sustained economic growth in the South East Zone. The actions that management in SMEs took to support and encourage workplace learning were thus matters of major interest, particularly because of the strong contention that there was a connection between how enterprises manage their people and the economic results achieved. This study and the emergent models contributed to an understanding of learning processes in SMEs and how management practices in SMEs may influence employee learning. It suggested practice that might, if addressed, improve both managerial performance and the quantity and quality of workplace learning.

It was found that the level of management that affected employee workplace learning for sustainable development were lower level, middle level and top level. That finding was not in agreement with the contention of Osaze and Yomere scale [30] who stated that the hierarchy of top middle and low frequencies is pyramidal but they did not stipulate the ratios got on the study. Okojie [31] in agreement with Onitiri [32] reviewed human capital investment activities in Nigeria and concluded that Human capital investment included investment in formal education, training as well as the services required to improve man's productive activities. The present studies in SME in South Eastern Nigeria showed how sustainable development was an important factor in productivity growth while available interviewed responses showed that productivity levels were high in Nigeria when the organization invests in employee informal workplace learning in form of coaching on the job learning and by trial of work activities. The present work fill the research gap of showing by use of questionnaire and cybernetic model that management had a positive effect on workplace learning for sustainable development in SMEs in SouthEastern Nigeria. In the empirical work of Billett [33] and Tannenbaum [34], workplace supervisors, other managers and co-workers, were supported as being important sources of work related learning. That differs in this study, where the managers' supervisors were not supported as being important sources of work related learning.

\subsection{The cybernetic sustainable development model}

In the course of this study, the researcher adjusted the model to suite the effects of management on employee workplace learning for sustainable development. 
This is done by using men, material (environmental condition), money and time as input and putting management of employee workplace learning (human resource management practices HRMP) as transform with control mechanism to actualize sustainable development in SME as output. This is illustrated in figure 1 below.

\section{Transform}

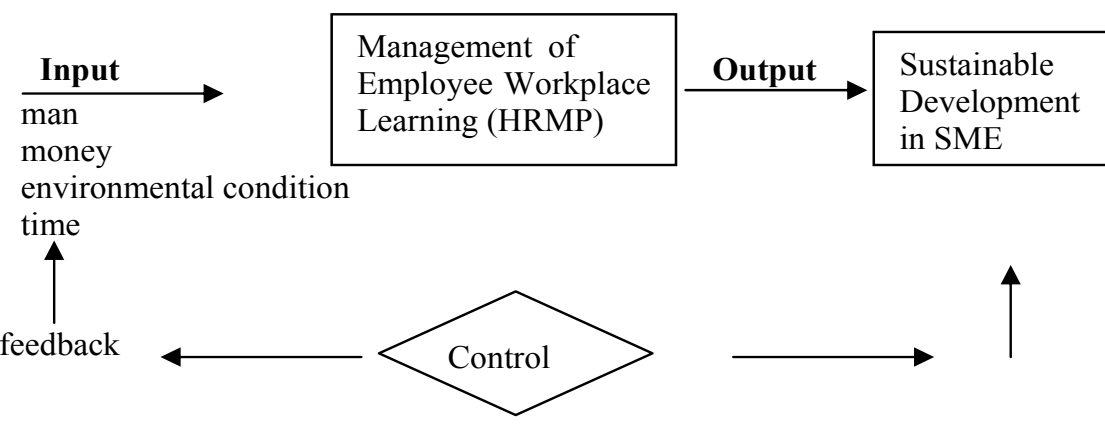

Figure 1: Showing system cybernetic sustainable development model.

It is finally concluded that using the cybernetic model, the management (the manager and supervisors) encouraging workplace learning with help of work mates, utilizing the human resource management practices under good environmental conditions, will facilitate the employee workplace learning experience outcome on production of goods and services for sustainable development of the employee in particular and the small manufacturing enterprise in general thereby improving the sustainability of economic growth of any nation.

\section{Recommendation}

The findings of this study suggested that there was vast potential for improving the context to support informal workplace learning, and managers might be neglecting their employee sustainable development role. In discussing the management employee development role, Coetzer [6] noted that social science research had clearly demonstrated the importance of this role in overall managerial effectiveness. Thus, management development programmes aimed at managers in small enterprises should embody elements that reflect the importance of the manager's people development role. For example, principles of adult learning and the skills of facilitating learning could be built into management sustainable development programmes. The feedback on the workgroup performance of the employee should be made available or known to them. This will enable the employee appraise the outcome of their developmental experiences with regards to sustainability. 


\section{References}

[1] Eneh, O.C. Small and medium enterprises in South East Nigeria Problems and Solution, Engudu: Welfare \& Industrial Promotion (WIPRO) International. pp 92005.

[2] Marquardt, M.J., Building and Organization, A Systems Approach to Quantum Improvement and Global Success. New York: McGraw-Hill pp 412-414 1999.

[3] Schein, E.H. How Can Organizations Learn Faster The Challenge of Entering the Green Room Sloan Management Review, 34(2) pp 85-86 1993.

[4] De Geus, A.P. Planning as Learning Harvard Business Review, 66 (2). pp $70-732005$.

[5] Grayson and Hodges Everybody's Business: Managing Risk and Opportunities in today's global society. Dorblin Kindersly. pp 388-390 2001.

[6] Coetzer, A.J. Developing Human Capital in Small Firms: a Conceptual Framework for Analyzing the Effects of Managers on Employee Learning, Research and Practice in Human Resource Management, 14(1). pp 10-15 2006.

[7] IIe N. M, Small Business Management: An Integrated Approach. Enugu: Utuson Nigeria Limited, Publisher. pp 200-205 2003.

[8] Griffin, R. A. Management, Boston New York Houghton Miffin Company. pp 9-12 2003.

[9] Ghoshal, S. and Bartlett, C.A, Changing the Role of Top Management: Beyond Structure to Process, Harvard Business Review, 30 (1). pp 86-87 1995.

[10] Kim, D.H. The link Between Individual and Organizational Learning, Stone Management Review, 4(8). pp 37-39 1993.

[11] Reynolds J., Caley and Mason R. How Do People Learn London: CIPA. pp 150-152 2002.

[12] Peddler, M., Boydell, T. and Burgoyne J. Towards The Learning Company, Management Education and Development, 20(1). pp 600-601 2004.

[13] Argyris C. Knowledge for Action: A guide to overcoming Barriers to Organizational Change, San Francisco Jossey Bass. pp 250-252 2004.

[14] Hicks, L. Gender and culture: attitudes Displayed by Managers in the Hotel Industry, Extract from an interview with hotel manager for unpublished doctoral research. pp 450-451 2008.

[15] Honey P. The debate starts here People Management 1 (10). pp 549-550 2004.

[16] Birchall and Lyons, L. Creating tomorrow's Organization, London, Pitman. pp 665-666 1995.

[17] Wakins, K.E. and Marsick, V.J. Sculpting the Learning Organization. San Francisco: Jossey-Bass pp 100-102 1993. 
[18] Eraut, M J, Alderton, G, Cole, G and Senker, P. Development of Knowledge and Skills in Employment, London: Economic and Social Research Council, pp 400-401 1998.

[19] Armstrong, M. Employee Reward, London: Institute of Personnel and Development. pp 558-560 2002.

[20] Holliday, R. Teachers as Learners: A Case Study of Conditions that Promote Teachers' Professional Learning. "A Thesis Submitted for the Degree of Doctor of Philosophy," Australia. University of New England, (An Extract). pp 12-16 1994.

[21] Nadler, D. A. Concepts for the management of organizational change, in M L., Tushman and W. L. Moore, Reading in the Management of information, New York Ballinger, pp 230-232 (1999.

[22] Wakins, K. E. and Marsick, V.J., Facility Organization: Making Learning Count. Vermont, New York: Gower. pp 100-101 1999.

[23] Marsick, V.J. New Paradigms for Learning in the Workplace, London: Croon Helm. pp 300-301 2001.

[24] Stern, E and Summerland, E, Workplace Learning, Culture and Performance, London: IPD. pp 552-554 1999.

[25] Keep, E. Corporate training strategies, in Perspective on Human Resources Management, Oxford: Blackwell. pp 500-501 2000.

[26] Bass, B M and Vaughan, J A. Training in Industry: The management of learning, London: Javistock. pp 200-202 1996.

[27] Imaga, E.U.L Business Policy in a Godly Society Enugu: Rohyce Kerex Publishers. pp 50-54 2005.

[28] Baridam D. M. Business Research Methods in Administrative Sciences. Port Harcourt: Bari Publishing Company. pp 100-102 2005.

[29] Zikmund, w. G. Business Research Methods. Orlando: The Dryden Press. pp 300-301 2000.

[30] Osaze B. E and Yoreme G. O. Business Policy and Strategy, Benin City BE: Osaze Incorporated 2006.

[31] Okojie, E. E. Human Capital Investment for Productivity Growth The Nigerian Economic and Financial Review (N.E.F.R) 1(1), June pp 10-11 2004.

[32] Onitiri, H.M.A, Productivity and Economic Development, Nigerian Economical and Financial Reviews 31 (1). pp 15-16 2005.

[33] Billett, S. Learning in the Workplace Strategies for Effective Practice, Crows Nest NSW Sydney: Allen and Unwin. pp 300-301 2001.

[34] Tannenbaum, S.I. Enhancing continuous learning: Diagnostic Findings from multiple companies, Human Resource Management, 36(4) pp 9-10 2002. 